\title{
Central Nervous System Strongyloidiasis and Cryptococcosis in an HIV-Infected Patient Starting Antiretroviral Therapy
}

\author{
Mónica Rodríguez, ${ }^{1}$ Paúl Flores, ${ }^{1}$ Víctor Ahumada, ${ }^{1}$ Lorena Vázquez-Vázquez, ${ }^{2}$ \\ Claudia Alvarado-de la Barrera, ${ }^{1}$ and Gustavo Reyes-Terán ${ }^{1}$ \\ ${ }^{1}$ Centro de Investigación en Enfermedades Infecciosas, Instituto Nacional de Enfermedades Respiratorias Ismael Cosío Villegas, \\ Calzada de Tlalpan 4502, Colonia Sección XVI, Delegación Tlalpan, 14080 México, DF, Mexico \\ ${ }^{2}$ Departamento de Patología, Instituto Nacional de Enfermedades Respiratorias Ismael Cosío Villegas, \\ Calzada de Tlalpan 4502, Colonia Sección XVI, Delegación Tlalpan, 14080 México, DF, Mexico
}

Correspondence should be addressed to Gustavo Reyes-Terán, gustavo.reyesteran@gmail.com

Received 23 May 2012; Revised 10 July 2012; Accepted 10 July 2012

Academic Editor: Nassim Kamar

Copyright ( $\odot 2012$ Mónica Rodríguez et al. This is an open access article distributed under the Creative Commons Attribution License, which permits unrestricted use, distribution, and reproduction in any medium, provided the original work is properly cited.

We report a case of Strongyloides stercoralis hyperinfection syndrome with central nervous system involvement, in a patient with late human immunodeficiency virus (HIV) infection starting antiretroviral therapy, in whom Strongyloides stercoralis larvae and Cryptococcus neoformans were isolated antemortem from cerebrospinal fluid. Our patient was not from an endemic region for the parasite, so strongyloidiasis was not originally suspected. For this reason, we conclude that Strongyloides stercoralis infection should be suspected in HIV-infected patients starting antiretroviral therapy in order to avoid potential fatal outcomes.

\section{Introduction}

Infection by Strongyloides stercoralis is endemic in tropical and subtropical regions of the world including Southern, Eastern, and Central Europe, Islands of the Caribbean, Latin America, Sub-Saharan Africa, and Southeast Asia. The number of people infected by this intestinal nematode is not well known, with estimates ranging from 30 to 100 million people living in 70 different countries [1]. In immunocompetent individuals, infection with $S$. stercoralis is usually asymptomatic, although pulmonary and gastrointestinal symptoms are common during acute and chronic infection. However, in immunocompromised patients, hyperinfection and dissemination of worms to ectopic sites (e.g., brain) causes severe illness. Both, hyperinfection and disseminated strongyloidiasis are more common in immunocompromised hosts [2]. Despite geographic overlaps, less than the expected number of cases of HIV-associated hyperinfection syndrome have been published [3-5]. Central nervous system (CNS) infection by $S$. stercoralis is uncommon, and the filariform larvae are found directly in the cerebrospinal fluid (CSF) rarely [6]. Here, we report a patient with late HIV-infection who had disseminated strongyloidiasis and cryptococcosis with CNS involvement soon after antiretroviral therapy initiation.

\section{Case Report}

A 30-year-old Mexican male patient was admitted to our institution due to a 3-week history of severe diarrhea, abdominal cramps, dry cough, progressive dyspnea, and fever. Patient informed consent for tests performed for clinical purposes using routine techniques was obtained on admission. His shortness of breath had progressed to resting dyspnea during the past 3 days. His vital signs were a heart rate of $112 / \mathrm{min}$, blood pressure of $80 / 50 \mathrm{~mm} \mathrm{Hg}$, and respiratory rate of $38 / \mathrm{min}$. He was febrile with a temperature of $38.7^{\circ} \mathrm{C}$. Physical examination disclosed polypnea, central cyanosis, disorientation, psychomotor agitation with no meningeal signs, oropharyngeal candidiasis, absence of cervical adenopathy, tachycardia, fine rales throughout both lung fields, absence of genital visceromegalies or abdominal megalies, and a painless genital ulcer on the back of the penis. 
Blood gasometry values were $\mathrm{pH}$ 7.52; $\mathrm{pCO}_{2} 18 ; \mathrm{pO}_{2} 41$; and $\mathrm{O}_{2}$ saturation was $72 \%$ on room air. He had initiated combined antiretroviral therapy during the previous month, with a CD4 T-cell count of 145 cells/ $\mu \mathrm{L}$ and a viral load of 256639 HIV RNA copies/mL $(5.4 \mathrm{log})$. Ten years before he had travelled to endemic areas for Strongyloides stercoralis in Mexico.

Ten days after admission, generalized ground glass opacities were evident on chest X-ray, so the patient was immediately transferred to the intensive care unit (ICU) and he received mechanical ventilation. On ICU admission, he had a leukocyte count of $7600 / \mu \mathrm{L}$; a platelet count of $377000 / \mu \mathrm{l} ; 89 \%$ neutrophils; $6 \%$ lymphocytes; $1 \%$ eosinophils; $\mathrm{Hb}$ level of $7.7 \mathrm{~g} / \mathrm{dL}$; Na level of $135 \mathrm{mEq} / \mathrm{L}$; LDH level of $563 \mathrm{U} / \mathrm{L}$; and ALP was of $544 \mathrm{IU} / \mathrm{L}$. With the presumed diagnosis of Pneumocystis carinii pneumonia (PCP) and respiratory distress syndrome in an immunocompromised patient, treatment with TMP/SMX was initiated together with ceftriaxone, clarithromycine, and fluconazol. Prednisone $40 \mathrm{mg}$ bid was administered via the enteral route for 5 days, followed by $40 \mathrm{mg}$ once daily. His condition gradually deteriorated, with persistent fever and ventilatory function impairment. Cerebrospinal fluid collected through lumbar puncture was clear, slightly turbid, with an opening pressure of $27 \mathrm{cms} \mathrm{H}_{2} \mathrm{O}$, with no cells, hyperproteinorraquia of $90 \mathrm{mg} / \mathrm{dL}$, and glucose of $64 \mathrm{mg} / \mathrm{dL}$. He had papilledema, and no focal neurological signs were detected. Cranial CT showed generalized cortical atrophy, unaltered ventricular size, and no structural lesions. Gram stain of CSF was negative, but India ink preparations revealed cryptococcal yeasts, and 2 Strongyloides stercoralis larvae were found in the cytological analysis (Figure 1). Therefore, administration of amphotericin B, flucytosine, ivermectin, and albendazol was initiated. Strongyloides stercoralis larvae were also found on bronchoalveolar lavage fluid cytology. Coproparasitoscopic and coprologic studies for Mycobacterium tuberculosis were negative, as well as CSF, blood and bronchoalveolar lavage cultures, and PCR. Cryptococcus neoformans was isolated latter from CSF, but it was not found in bronchoalveolar lavage nor in blood culture. The CD4 T-cell count was of 89 cells $/ \mu \mathrm{L}$, and the viral load had decreased to 318 HIV RNA copies/mL (2.5 log). The patient developed multiple organ system failure and died 14 days after ICU admission.

\section{Discussion}

We have been able to identify only four cases in the literature of HIV-infected patients with disseminated strongyloidiasis and CNS involvement evidenced by direct finding of filariform larvae in CSF $[6,7]$, in meningeal vessels [8], or in meningeal spaces [9]. We report a case of Strongyloides stercoralis hyperinfection syndrome and disseminated cryptococcosis, in a patient with late HIV infection in whom S. stercoralis larvae and Cryptococcus neoformans were isolated antemortem from cerebrospinal fluid. Pulmonary and meningeal signs of parasite infection were predominant in our patient.

When the intact skin of a susceptible host interacts with the infective filariform larvae living in soil, transcutaneous

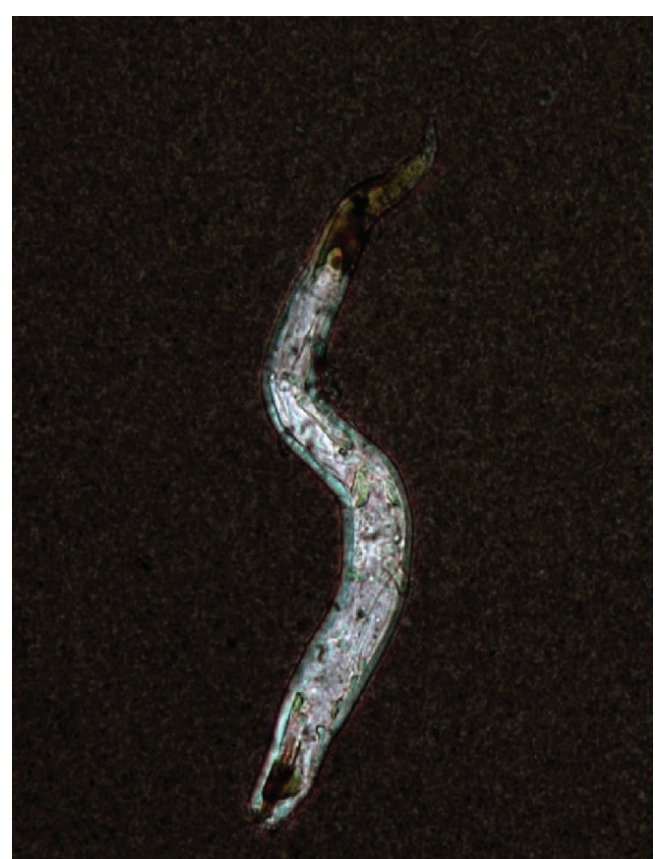

Figure 1: Rhabditiform larva of Strongyloides stercoralis recovered from cerebrospinal fluid sediment (India ink, x100).

infection occurs and the filariform larvae travel to the blood stream via subcutaneous lymphatics reaching the pulmonary circulation. Individuals infected by $S$. stercoralis may remain asymptomatic for long periods or they may course with acute or chronic nonspecific symptoms, but they can still develop mortal disease years after the exposure [10]. For this reason, diagnosis of strongyloidiasis relies on a high index of clinical suspicion, which is particularly difficult in those HIV-infected subjects who, as our patient, do not present eosinophilia, a common laboratory finding in immunocompetent population infected with this nematode [4]. In any case, the most important test for demonstrating $S$. stercoralis remains the repeated examination of stool over a number of consecutive days [11]. In our patient, direct examination of the parasite in CSF was conclusive for the diagnosis of strongyloidiasis.

Ivermectin $200 \mathrm{mg} / \mathrm{kg} /$ day is the treatment of choice for strongyloidiasis and, for patients with hyperinfection or disseminated infection, should be continued for at least 7-10 days or until resolution of symptoms [2]. However, deficient responses to conventional treatment have been reported in HIV-infected patients due to malabsorption and ileus [12] or to undefined causes [3]. Hence, a close followup and a more prolonged treatment with ivermectin or alternative agents (e.g., albendazol) have been considered in these cases. Our patient had CNS symptoms so the screening for opportunistic infections was done in CSF. We would like to emphasize that infection by $S$. stercoralis was then an incidental finding since Mexico City is not an endemic region for this parasite.

Here, we present a patient with infection by Strongyloides stercoralis and Cryptococcus neoformans, who had an apparent clinical deterioration soon after combined antiretroviral 
therapy initiation, and a $2.9 \log$ decrease in viral load. Therefore, the clinical picture is consistent with an event of unmasking immune reconstitution inflammatory syndrome (IRIS). This condition occurs as a result of unmasking of clinically silent infection and is characterized by atypical exuberant inflammation and/or an accelerated clinical presentation, suggesting a restoration of antigen-specific immunity [13]. Strongyloides stercoralis might have been the main driver of IRIS [14], but we cannot exclude the contribution or perhaps the leading role of Cryptococcus neoformans in this episode [15]. In addition, the use of use of high doses of corticosteroids in patients with acquired immunodeficiency syndrome (AIDS) and cryptococcal meningitis has been associated to decreased survival. By consequence, the potential negative effects of prednisone in our patient should be considered.

We conclude that Strongyloides stercoralis infection should be suspected in HIV-infected patients starting antiretroviral therapy, even if they come from nonendemic areas, as subdiagnosis and therapeutic failure in this population may lead to fatal outcomes.

\section{Conflict of Interests}

The authors declare that they have no conflict of interests.

\section{Acknowledgments}

This work was supported by grants from the Mexican Government (Comisión de Equidad y Género de la Honorable Cámara de Diputados de la LXI Legislatura de México) and Fundación México Vivo (http://www.mexicovivo.org/). The funders had no role in study design, data collection and analysis, decision to publish, or preparation of the paper.

\section{References}

[1] A. A. Siddiqui and S. L. Berk, "Diagnosis of Strongyloides stercoralis infection," Clinical Infectious Diseases, vol. 33, no. 7, pp. 1040-1047, 2001.

[2] M. Walker and J. R. Zunt, "Parasitic central nervous system infections in immunocompromised hosts," Clinical Infectious Diseases, vol. 40, no. 7, pp. 1005-1015, 2005.

[3] K. D. Lessnau, S. Can, and W. Talavera, "Disseminated Strongyloides stercoralis in human immunodeficiency virusinfected patients: treatment failure and a review of the literature," Chest, vol. 104, no. 1, pp. 119-122, 1993.

[4] M. M. Gompels, J. Todd, B. S. Peters, J. Main, and A. J. Pinching, "Disseminated strongyloidiasis in AIDS: uncommon but important," AIDS, vol. 5, no. 3, pp. 329-332, 1991.

[5] S. Maayan, G. P. Wormser, J. Widerhorn, E. R. Sy, Y. H. Kim, and J. A. Ernst, "Strongyloides stercoralis hyperinfection in a patient with the acquired immune deficiency syndrome," American Journal of Medicine, vol. 83, no. 5, pp. 945-948, 1987.

[6] O. M. Takayanagui, M. M. Lofrano, M. B. M. Araujo, and L. Chimelli, "Detection of Strongyloides stercoralis in the cerebrospinal fluid of a patient with acquired immunodeficiency syndrome," Neurology, vol. 45, no. 1, pp. 193-194, 1995.

[7] J. P. Dutcher, S. L. Marcus, H. B. Tanowitz, M. Wittner, J. Z. Fuks, and P. H. Wiernik, "Disseminated strongyloidiasis with central nervous system involvement diagnosed antemortem in a patient with AIDS and Burkitt's lymphoma," Cancer, vol. 66, no. 11, pp. 2417-2420, 1990.

[8] K. M. Cahill and M. Shevchuk, "Fulminant, systemic strongyloidiasis in AIDS," Annals of Tropical Medicine and Parasitology, vol. 90, no. 3, pp. 313-318, 1996.

[9] S. Morgello, F. M. Soifer, C. S. Lin, and D. E. Wolfe, "Central nervous system Strongyloides stercoralis in acquired immunodeficiency syndrome: a report of two cases and review of the literature," Acta Neuropathologica, vol. 86, no. 3, pp. 285-288, 1993.

[10] C. S. Lam, M. K. H. Tong, K. M. Chan, and Y. P. Siu, "Disseminated strongyloidiasis: a retrospective study of clinical course and outcome," European Journal of Clinical Microbiology and Infectious Diseases, vol. 25, no. 1, pp. 14-18, 2006.

[11] WGO Practice Guideline Management of Strongyloidiasis, 2004, http://www.worldgastroenterology.org/assets/downloads/en/pdf/guidelines/15_management_strongyloidiasis_en .pdf.

[12] F. D. Rivero, L. E. Rivero, L. Kremer, L. Allende, and R. Casero, "Strongyloides stercoralis y VIH: un caso de infección diseminada en una zona no endémica," Revista Argentina De Microbiología, vol. 38, no. 3, pp. 137-139, 2006.

[13] D. M. Murdoch, W. D. F. Venter, A. Van Rie, and C. Feldman, "Immune reconstitution inflammatory syndrome (IRIS): review of common infectious manifestations and treatment options," AIDS Research and Therapy, vol. 4, article 9, pp. 1-10, 2007.

[14] M. Lanzafame, F. Faggian, E. Lattuada, D. Antolini, and S. Vento, "Strongyloidiasis in an HIV-1-infected patient affer highly active antiretroviral therapy-induced immune restoration," Journal of Infectious Diseases, vol. 191, no. 6, p. 1027, 2005.

[15] S. K. Cinti, W. S. Armstrong, and C. A. Kauffman, "Case report. Recurrence of increased intracranial pressure with antiretroviral therapy in an AIDS patient with cryptococcal meningitis," Mycoses, vol. 44, no. 11-12, pp. 497-501, 2001. 


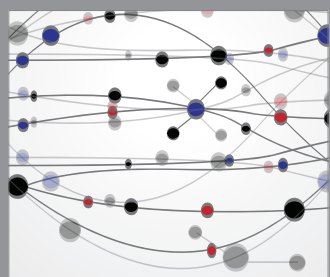

The Scientific World Journal
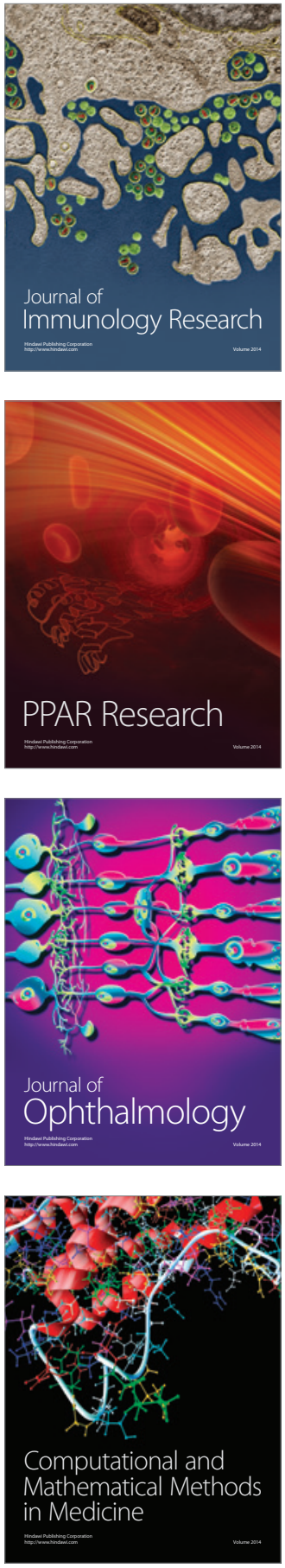

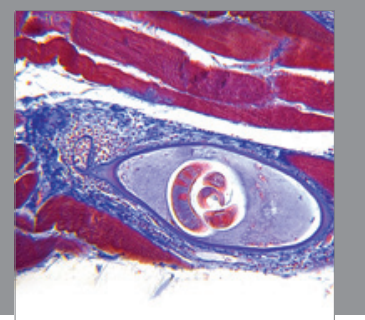

Gastroenterology

Research and Practice
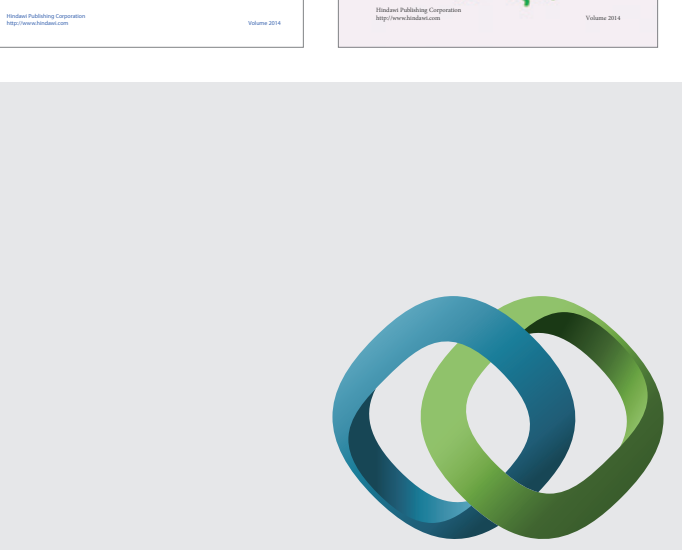

\section{Hindawi}

Submit your manuscripts at

http://www.hindawi.com
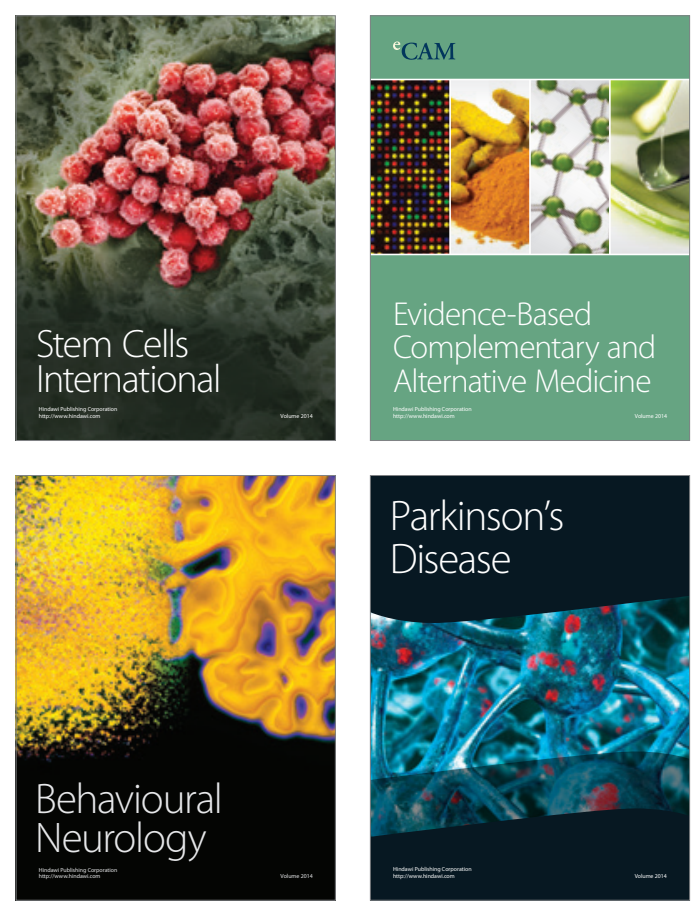

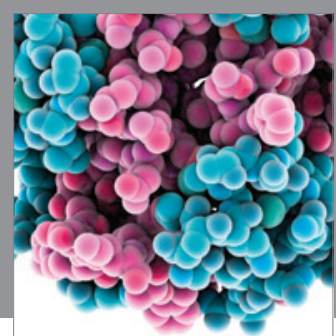

Journal of
Diabetes Research

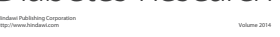

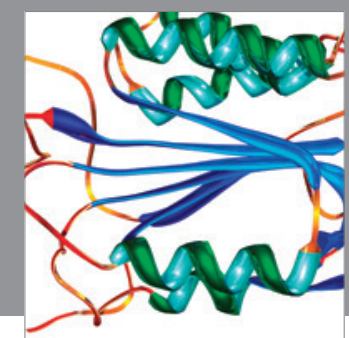

Disease Markers
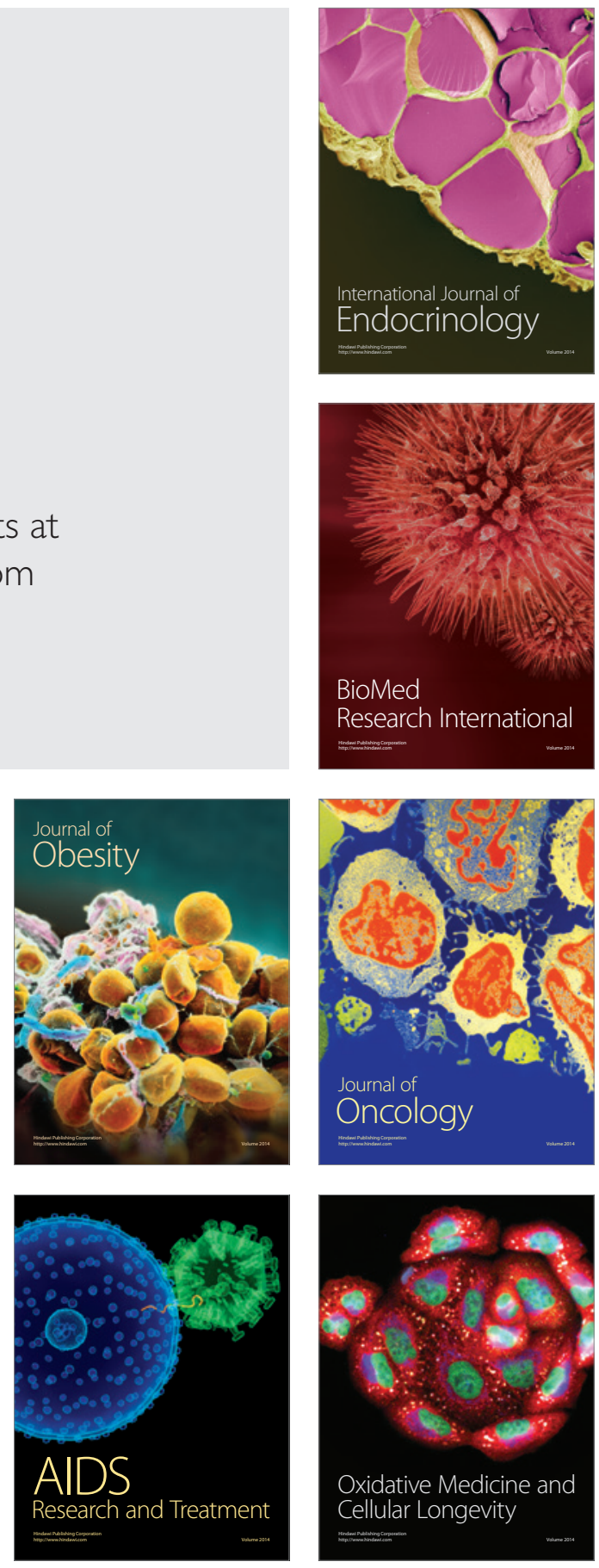